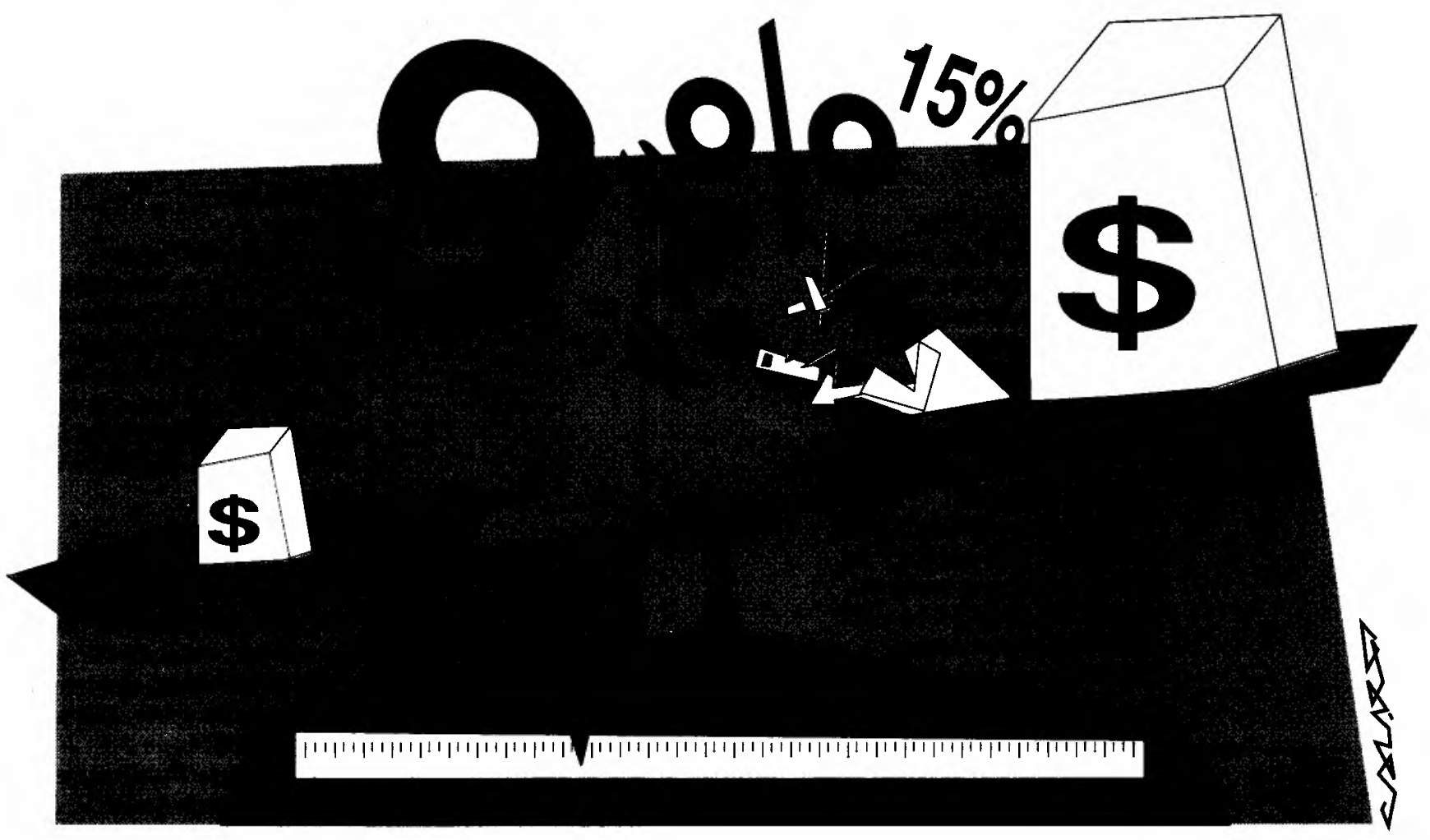

\title{
ALGUMAS OBSERVAÇÕES SOBRE A MARGEM DE CONTRIBUIÇÃO
}

"Dependendo dos métodos utilizados para apropriar os custos fixos, alguns produtos mostrarão lucro e outros prejuízo. Atualmente os custos totais perderam sua importância para efeito de análise e o que importa na apuração dos custos se faz nas vendas e nos custos de cada produto".

A. Matz

\section{Ivan Pinto Dias}

Professor Adjunto do Departamento de

Contabilidade, Finanças e Controle da EAESP/

FGV.

* RESUMO: O artigo procura mostrar alguns conceitos de há muito conhecidos e empregados pelos economistas, no campo de administração contábil e financeira.

$O$ conceito de margem de contribuição, mostra novidades no cálculo do ponto de equilíbrio. A área de significância dos dados é importante para não chegar-se a projeções absurdas. É mostrada também a falácia da análise do custo total, onde os custos fixos, conforme sua programação, apresentam custos totais diferentes.

Finalmente, é apresentado um gráfico para mostrar a importância da margem de contribuição.
* PALAVRAS-CHAVE: Margem de contribuição, indice de margem de contribuição, nivel de significância dos dados, custo total, custo variável, custo fixo, ponto de equilibrio.

* ABSTRACT: The paper analyzes some concepts in the field of Financial and Management Accounting that are well known by economists.

The concept of contribution margin adds new notions in the computation of the break-even point. The relevant range of the data is important to avoid absurd prospections. The fallacy of the analysis of total costs, where the fixed costs, as they are allocated show different total costs, is also indicated.

Finnaly, it is shwon a chart where the relevance of the contribution margin can be seen.

* KEY WORDS: Contribution margin, contribution margin ratio, relevant range, total cost, variable cost, fixed cost breakeven point.

São Paulo, 32(3): 36-45

Jul./Ago. 1992 


\section{INTRODUÇÃO}

Ultimamente, têm sido utilizados, no campo da administração contábil e financeira, noções e conceitos de há muito conhecidos e empregados pelos economistas.

Tal fato ocorreu nesta última década e, embora existam várias disparidades na terminologia $e$, às vezes, até nas próprias definições, lembramos que os mesmos foram transportados da ciência econômica para a administração contábil e financeira. Apesar de, tanto naquela quanto nesta, os autores divergirem, muitas vezes, entre $\mathrm{si}$, não há dúvida de que muito bom proveito pode ser tirado das contribuições recebidas.

Uma das idéias novas é que a própria expressão "ponto de equilíbrio"1 foi abandonada em favor de outra, "relaçôes entre custo-volume-lucro", onde o ponto de equilíbrio é apenas uma das partes do estudo dessas relações. ${ }^{2}$

O conceito de margem de contribuiçāo, sobre o qual iremos fazer algumas observações no presente artigo, também é relativamente novo no campo da administração contábil e finaceira. ${ }^{3}$

\section{Muitas investigaçôes estatísticas meticulosas encontraram para diversas empresas a função produção $e$ custo total como sendo linear.}

Veremos o seu significado, quando calcularmos o ponto de equilíbrio, e verificaremos então a falácia da análise pelo custo total, pois, conforme pretendemos demonstrar, o índice de margem de contribuição será o grande instrumento do administrador de empresas para determinação da lucratividade de cada produto.

Utilizaremos exemplos bem simples, com números pequenos e quantias arredondadas, com o fito de melhor explanar o assunto, pois, assim, acreditamos que os leitores poderão colocar em uso as idéias a serem discutidas mais rápida e facilmente.

\section{O CONCEITO DE MARGEM DE CONTRIBUIÇÃO}

Sabemos que os custos de uma empresa podem ser agrupados em custos fixos e custos variáveis. Custos fixos são aqueles que tendem a permanecer constantes em seu total, embora haja variações no volume de atividades da empresa, ou seja, apesar de o seu total poder variar de um período para outro. Porém, em cada período de tempo ele não é afetado pela quantidade de produção ou vendas. Um exemplo típico são os impostos prediais, que podem aumentar de um ano para outro, porém permanecem constantes em um dado ano. Custos variáveis são aqueles que em seu total variam de acordo com as alterações no volume de atividades, como é o caso das matérias-primas, luz e força etc., porém unitariamente não variam. ${ }^{4}$

A margem de contribuição, conhecida também por "contribuição para o lucro", "contribuição para cobrir o custo fixo e proporcionar lucro", "contribuição para o custo fixo", "saldo marginal", "receita marginal", "lucro marginal" e outras denominações, se refere à diferença entre o preço da venda e o custo variável, ou seja:

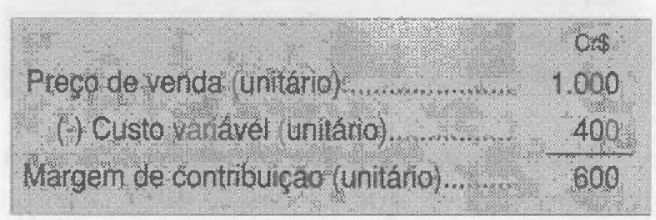

Isso significa que cada $\mathrm{Cr} \$ 1,00$ de vendas "contribui" com Cr\$0,60-ou, melhor ainda, cada unidade vendida "contribui" com $\mathrm{Cr} \$ 600$ - para cobrir o total do custo fixo da empresa e, se possível, conforme o volume de unidades produzidas e/ou vendidas, também para proporcionar lucro.

O conceito de margem de contribuição nos leva também à noção da Demonstração Marginal da Conta de Lucros e Perdas, que é antiortodoxa. Supondo-se, por exemplo, que a empresa em consideração esteja fabricando e/ ou vendendo 600 unidades e que seu custo fixo seja de Cr\$ 300.000 , temos:

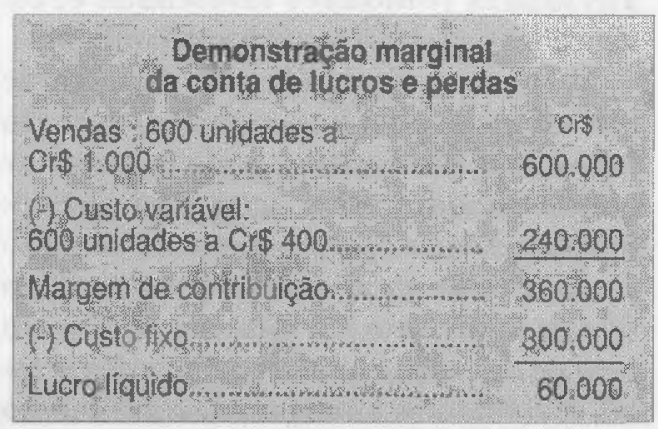

1. "Ponto de equilibrio" é tradução livre do conceito em inglès conheci. do como break-even point, isto é volume de vendas elou produçăo onde as receitas săo iguais aos cus. tos e não há lucro nem prejuízo.

2. Cf. HORNEGREEN, C.T. Cost Accounting, a Managerial Emphasis. Englewood Citfts, Prentice-Hall, Inc., 1962, p. 42. Os interessados nesse assuntopodem consultar ainda DIAS, I. P. "A Análise das Relaçóes entre Custo-Volume-Lucro". In: QUILICI, F.; HOPP, J. C. \& MONTE CARMELO, M. H. Princípios de Administração Contábile Financeirana Pequena Emoresa Brasileira, Rio de Janeiro, FGV, 1968

3. Um artigo muito bom, que mostra a importância dos conceitos de custos dos economistas nos últimos progressos havidos na contabilidade de custos, é o de EARLEY, J. S. "Recent Developments in Cost Acounting and the Marginal Analysis". Journal of Political Economy, junho, 1955, pp. 227-42, apud COLBERG, M. R.; 8RADFORD, W. C. \& ALT, R. M. Business Economics, Principles and cases. Homewood, Richard D. Inwin, Inc. 1957 (ediç̧̃o revista), p. 133.

4. Apresentamos somente de modo sumário essa questäo de custos fixos e cusios variáveis, os quais, da maneira em que foram conceituados, diferem das noçóes de custos apresentadas de modo geral pelos economistas. Alguns artigos em português, que tratam dessa questăo e suas aplicaçōes, são: SCHOEPS, W. "O Método de Custeio Direto", Revista de Administraçāo de Empre sas, 32(2):44-57, jul.-ago. 1992; GRUNEWALD A. E. "Planejamento Financeiro e Deferminacāo do Lucro", Revisfa de Administração de Empresas, 3(9):69-89, out.-dez. 1963; WEROLIN A. E. "A Elabora. ção de um Orçamento Variável", 
Podemos obter o índice do custo variável do exemplo acima, que é a porcentagem do custo variável unitário em relação ao preço de venda unitário, isto é:

$\begin{gathered}\text { Custo variável } \\ \frac{\text { Unitário }}{\text { Preco de venda }} \\ \text { unitário }\end{gathered}=\frac{\operatorname{cr} \$ 400}{\operatorname{cr} \$ 1,000} \times 100=40 \%$

Isso significa que, no caso em questão, $40 \%$ do preço de venda unitário é representado pelo custo variável unitário.

Logicamente, tal indice também pode ser obtido trabalhando-se com o custo variável total e a receita total de vendas em um certo nível de atividades. Utilizando-se os dados da Demonstração Marginal da Conta de Lucros e Perdas acima, pode-se Revistade Administraçäo de Empresas, 5(16):127-43, set. 1965. Para o importante problema da separação do elemento fixo e do elemento variável dos custos semi-variáveis, também denominados de custos semifixos, consulte-se: WELSCH, G. A. Budgeting, Protit Planning and Control. $2^{a}$ edição. Englewood Clifts, Prentice-hall, Inc., 1964, pp.210-24; HORNEGREEN, C. T. Op. cit. pp. 193-98;BLACK,H.A.\&CHAMPION, J. E. Accounting in Business Decisions, Theory, Method and Use, EnglewoodCliffs, Prentice-Hall, Inc. 1961, pp.295-306; COX, R. G. Principles of Accounting, Nova lorque, The Ronaid Press Company, 1961, pp.473-75; TSE, J. Y. D. Profit Planning Through Volume-Cost Analysis, Nova lorque, The Macrillan Company, 1960, p.118.

5. Alguns autores americanos denominam esse indice também de $P N$ ratio ou Profit Nolume ratio, que podemos traduzir por "indice do Lucrol Volume ${ }^{n}$, porém, como Matz, Currye Frank chamam a atençâo, essa expressão pode dar motivos a confusão porque: "... o indice nẫo é obtido como conseqüência da divisão do lucro pelo volume, pois, na verdade, é a porcentagem de cada dólar de unidade vendida que permanece, depois que dela foi deduzida a porcentagem do custo variável..." Ver: MATZ, A.; CURRY, O. J. \& FRANK, G.W. CostAccounting, Management Operational Toolfor Planning, Control and Analysis, Cincinnati, SouthWestemPublishing Co., 1962, p. 742. perceber que:

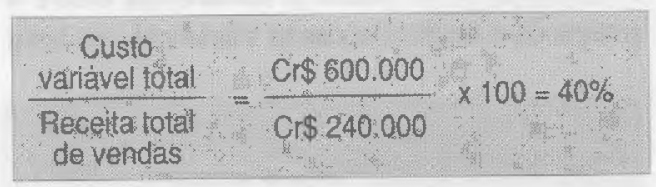
custo variável, que no caso é $40 \%$, obtémse $60 \%$, porcentagem esta que é denominada de índice da margem de contribuição, ou seja:

$\begin{aligned} & \text { Indice de margem } \\ & \text { de contribuiçá }\end{aligned}=100 \%-$ indice de custo

\section{Portanto:}

\section{$\begin{aligned} & \text { Indice de margem } \\ & \text { de contribuiçăo }\end{aligned}=100 \%-40 \%=60 \%$}

O índice da margem de contribuição cada unidade vendida ou o total das vendas "contribui" para cobrir o total do custo fixo e, se possível, conforme o nível de atividades (unidades fabricadas e/ou vendidas), proporcionar lucro também.

Naturalmente, o índice da margem de contribuição, sendo o complemento do índice do custo variável, pode também ser obtido dividindo-se a margem de contribuição unitária (preço de venda unitário menos o custo variável unitário) pelo preço de venda unitário ou, raciocinando-se em termos de receita total e custo variável total, dividindo-se a margem de contribuição
Subtraindo-se agora de $100 \%$ o índice do significa, em termos porcentuais, quanto

total (receita total de vendas menos o custo variável total) pela receita total de vendas, isto é, empregando-se os dados anteriores.

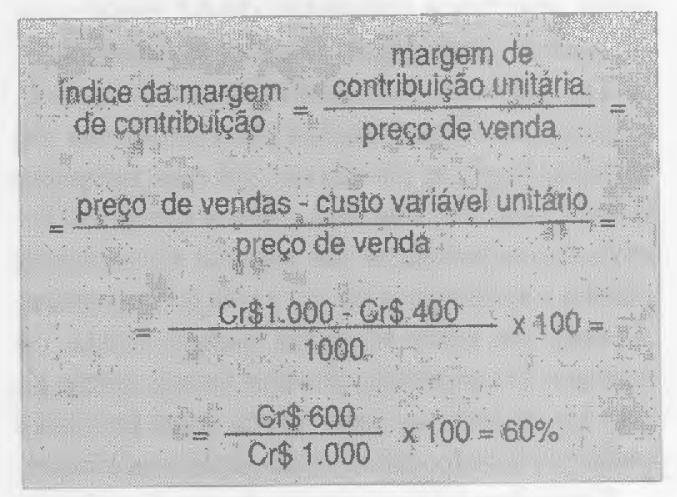

Ou então:

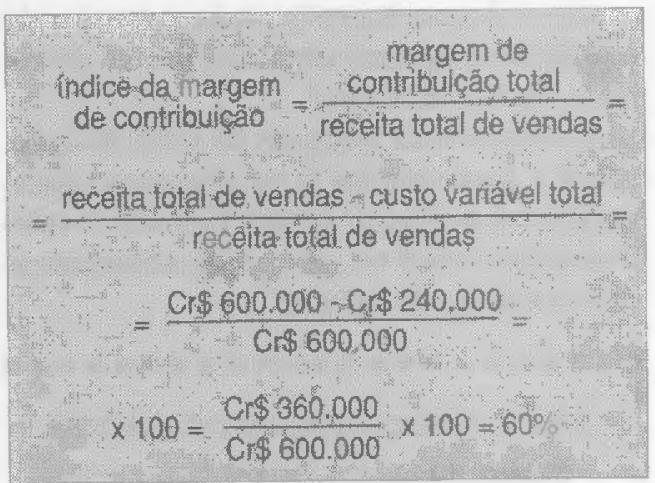

\section{PONTO DE EQUILÍBRIO}

Uma vez obtida a margem de contribuição e o seu respectivo índice, o ponto de equilíbrio da empresa que estamos exemplificando pode ser calculado das seguintes maneiras:

\begin{tabular}{|c|c|}
\hline & custo fixo \\
\hline (em unidades) & $\begin{array}{c}\text { margem de contribuiçáco } \\
\text { unitảia }\end{array}$ \\
\hline
\end{tabular}

Portanto:

Ponto de equilibrio
(em unidades)

Evidentemente, multiplicando-se 500 unidades por $\mathrm{Cr} \$ 1.000$ (preço de venda unitário) obtém-se Cr $\$ 500.000$, que é o volume monetário de produção e/ou vendas para atingir-se o ponto de equilíbrio. 
Temos ainda:

$\begin{aligned} & \text { Ponto de equilibrio } \\ & \text { (volume monetário) }\end{aligned}=\frac{\text { custo fixo }}{\text { índice de margem }}$
de contribuiçăo

Logo:

$\begin{aligned} & \text { Ponto de equilibrio } \\ & \text { (volume monetário) }\end{aligned}=\frac{\operatorname{Cr} \$ 300.000}{\operatorname{Cr} \$ 0,60}=\operatorname{Cr} \$ 500.000$

Naturalmente, dividindo-se $\mathrm{Cr} \$ 500.000$ por Cr $\$ 1.000$ (preço de venda unitário), obtém-se 500, que é o número de unidades produzidas e/ou vendidas no ponto de equilibrio.

O gráfico 1 apresenta também novidades, quando se trabalha com o conceito de margem de contribuição, em comparação à maneira tradicional de apresentá-lo, conforme se percebe nesse gráfico, onde pressupôs-se que a capacidade total da empresa é de 1.000 unidades.

No gráfico 1, a reta do custo variável foi traçada em primeiro lugar, a reta do custo fixo é traçada como uma paralela a do custo variável, mostrando o total cumulativo do custo fixo mais o custo variável. Desse modo, tem-se a vantagem de mostrar qual é a "recuperação" do custo fixo nos vários níveis de atividades, isto é, que "contribuição" o volume de produção e/ ou vendas fará para cobrir o custo fixo, "contribuição" esta medida pela distância vertical entre a reta do custo variável e a reta da receita total. Naturalmente, o que restar, depois de coberto o custo fixo, será. lucro.

Conforme se percebe no gráfico 1, a produção e/ou venda de 600 unidades "contribuirá" com Cr\$360.000 para a empresa (receita total menos custo variável total, ou seja, $\operatorname{Cr} \$ 600.000-\operatorname{Cr} \$ 240.000$ ). Uma vez que o custo fixo é Cr $\$ 300.000$, sobrarão ainda Cr\$ 60.000 de lucro. Se o nível de atividades for de 400 unidades, por exemplo, a "contribuição" será de Cr\$ 240.000 (Cr $\$ 400.000$ - Cr $\$ 160.000$ ), para um custo fixo de $\mathrm{Cr} \$ 300.000$, o que significa um prejuízo de $\mathrm{Cr} \$ 40.000$. Porćm, mesmo assim, pode ser interessante para a empresa continuar a curto prazo operando com prejuízo, pois, enquanto a receita de vendas cobrir o custo variável, tudo aquilo que obtiver acima do custo variável será uma "contribuição" que ajudará a cobrir o custo fixo. ${ }^{6}$ Assim, no último exemplo, o prejuizo será de Cr $\$ 40.000$. Todavia, se a empresa fechar ou não produzir e/ou vender, seu prejuízo será de pelo menos Cr\$300.000 (igual ao custo fixo). Como vemos, é possível, então, saber não só qual é o ponto de equilíbrio, mas também qual é a "recuperação" do custo fixo, aos vários níveis de atividades.

\section{ÁREA DE SIGNIFICÂNCIA}

Muitas pessoas, quando utilizam os conceitos proporcionados pela análise entre custo-volume-lucro, esquecem-se de uma limitação principal: a área de significância dos dados. ${ }^{7}$

Quando trabalhamos com os dados para a obtenção, por exemplo, do ponto de equilíbrio, não nos devemos esquecer de que os mesmos foram obtidos de uma empresa que necessariamente não estava trabalhando em $100 \%$ de sua capacidade ou em vários níveis intermediários de sua capacidade total.

Assim, para ilustrar melhor a questão, no caso da empresa que exemplificamos até agora, supondo que a mesma sempre funcionou entre $40 \%$ e $70 \%$ de sua capacidade máxima, isto é, produzindo e/ou vendendo 400 a 700 unidades respectivamente, bem como os dados sobre o comportamento de seus custos obtidos dentro
6. Os economistas, em sua maior parte, advogam também esta idéia. Veja-se, por exemplo: COLBERG, M. R. et alii. Op. cit., p.139; e LEFTWITCH, R. H. The Price System and Resource Allocation. (Edição revista) Nova lorque, Hoitt, Rinehart and Winston, 1960, pp.177-79.

7. Em muitas obras de autores norteamericanos, esta idéia é conhecida como relevant range. Veja-se, por exemplo: HORNOEGREEN, C. T. Op. cit., p. 49; e WELSCH, G. H. Op. cit., p. 332.

Gráfico 1

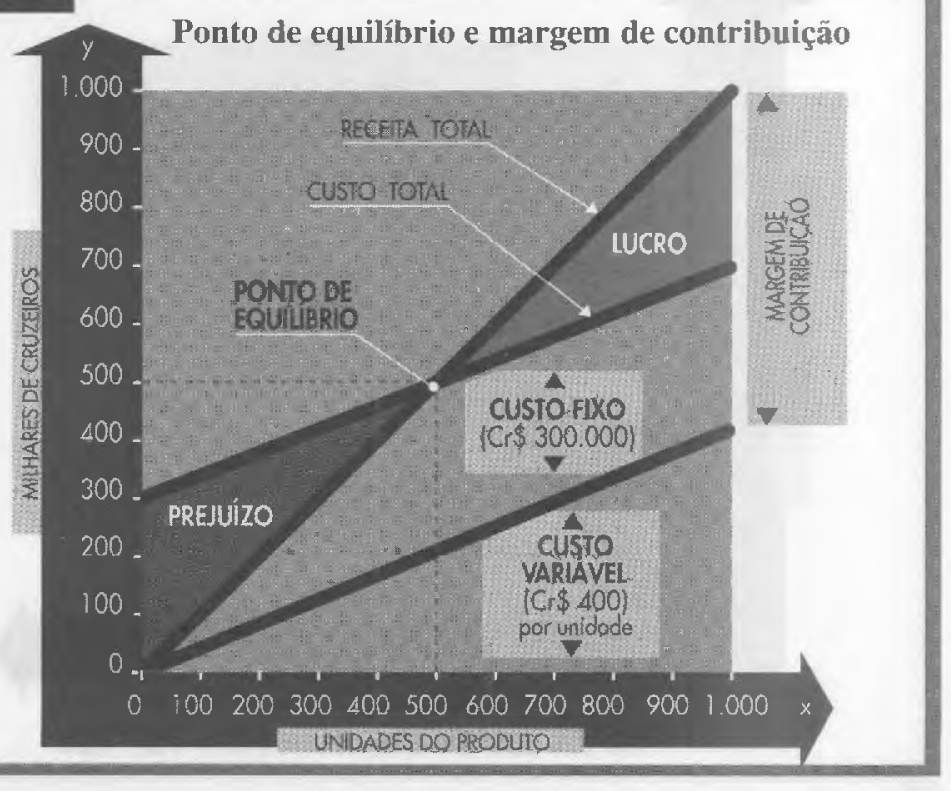


8. Veja-se, por exemplo: COLBERT, M.R. et alii. Op. cit, capitul 0 4, especialmente pp. 137-39; a LEFTWICH, R. H. Op. cil., capítulos $7,8,9$ e 10, principalmente op. 174 e 205, em que o ponto ce vista dos economistas é muito bem exolicado.

9. SAMUELSON, P. A. Economics, An Introductory Analysis. $4^{8}$ edição. Nova lorque, McGraw-Hill BookCO., Inc., 1958, po.483-84.

10. DEAN, J. "Cost Structures of Enterprises and Break-Even Charts". American Economic Review, maio de 1948, p.159. Sobre essa questão, veja-se ainda KEMPSTER, J. H. "Break-Even Analysis - Carnmon Ground for the Economist and the CostAccountant". NACA Bulletin, fev. 1949, especialmente p.712; bem como SOLDOFSKY, R. M. "Accountant's vs. Economist's Concepts of Break-Even Analysis". NACA Bulletin, dez. 1959, pp.5-18. desses limites, o máximo que se pode fazer é, empregando técnicas estatísticas, procurar expandir esse âmbito de atividades, dentro do qual as previsões feitas são válidas com certos limites de confiança. Portanto, supondo-se ainda que deste modo foi possivel expandir e determinar que a área de significância dos dados é entre $30 \%$ e $80 \%$ da capacidade máxima, isso significará que não serão válidas quaisquer projeções fora de tais limites, conforme pode ser observado no gráfico 2 .

Nesse gráfico, pode-se notar a importância desse conceito de área de significância a fim de não se chegar a projeções absurdas (fora dos limites predeterminados pela área de significância), para depois verificar que não aconteceu o que estava previsto e pensar-se então erroneamente que "na prática não funcionam os conceitos de análise das relações entre custo-volume-lucro".

Resta ainda verificar o fato de que nem todos os economistas estão de acordo com a hipótese de que o custo variável unitário seja constante e o seu total varie exatamente na proporção dos níveis de atividades, uma vez que, devido à "Lei das Proporçōes Variáveis", a linha que representa o custo total seria uma curva, assim como seria curva também a linha representativa da receita total, pois, a não ser que a empresa operasse em regime de concorrência

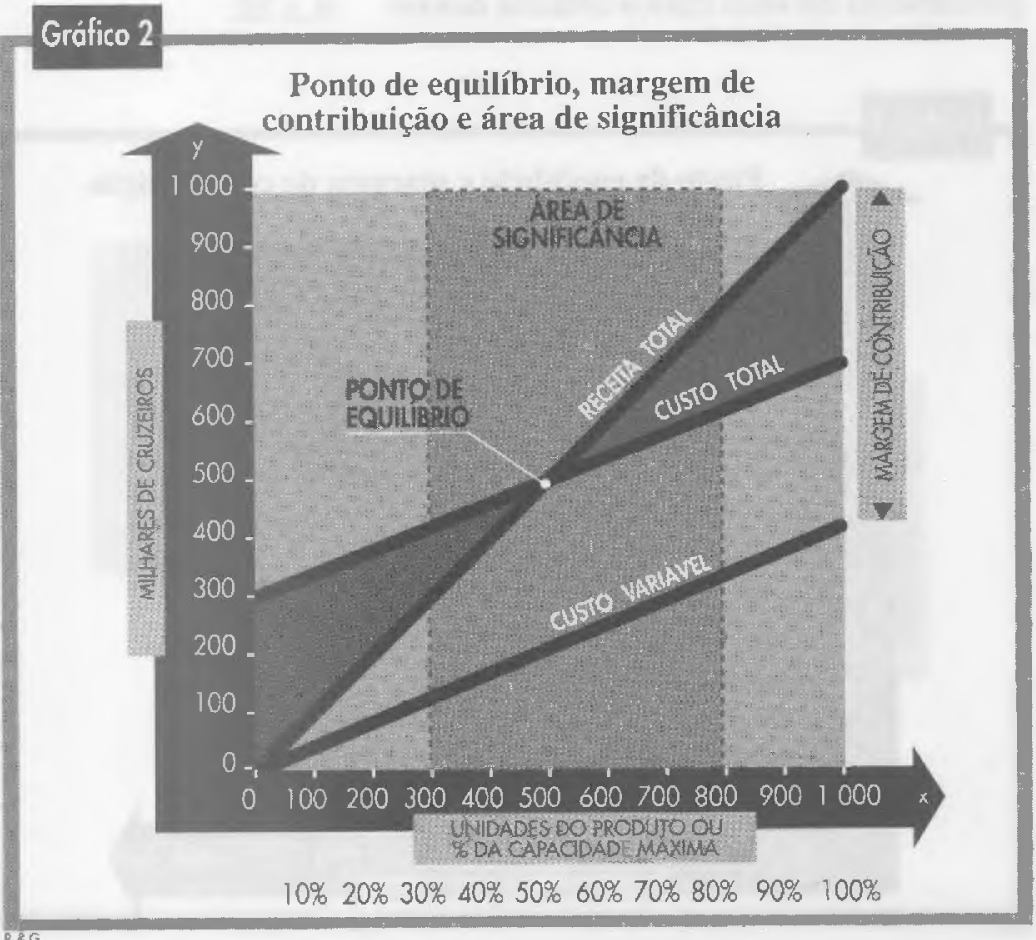

perfeita, haveria necessidade de diminuir os preços, a fim de aumentar as quantidades vendidas". ${ }^{8}$

Todavia, economistas como Samuelson, por exemplo, acham que a linha de custo total pode ser representada por uma linha reta, assim como a linha da receita total, embora isso seja apenas uma "aproximação tolerável da verdade ${ }^{\prime r} .{ }^{9}$

Finalmente, um dos mais conceituados economistas de empresas no momento, Joel Dean, é de opinião que "embora a linearidade da função do custo total nos gráficos de ponto de equilíbrio perturbe muitos economistas, pois não está de acordo com as curvas generalizadas da teoria... muitas investigaçōes estatísticas meticulosas encontraram para diversas empresas a função produção $e$ custo total como sendo Iinear...". ${ }^{10}$

Desta maneira, acreditamos que os leitores deste artigo, ao empregarem os conceitos explanados até agora, desde que observem as limitações impostas pela área de significância dos dados, terão conhecimento das limitações e assim evitarão problemas oriundos da inadvertência.

\section{A FALÁCIA DA ANÁLISE PELO CUSTO TOTAL}

Quando uma empresa fabrica e/ou vende mais de um produto, seria necessário fazer um gráfico do ponto de equilíbrio para cada um dos produtos, a fim de conhecer o lucro proporcionado por cada um deles, bem como poder responder pelo menos às seguintes perguntas:

- Qual o produto a ser mais promovido e vendido?

- Qual o produto mais lucrativo?

- Que decisōes devem ser tomadas com vistas à política de determinação de preços da empresa?

Todavia, para se fazer um gráfico, mostrando o ponto de equilíbrio para cada produto, seria necessário a propriar o custo fixo entre os vários produtos, porém essa apropriação, por mais lógica que seja a base escolhida, nem sempre é perfeita, podendo, não raramentc, dar uma idéia errônea da realidade.

Assim, a fim de melhor expor a questão, supondo que os dados existentes sobre uma firma hipotética, cujo custo fixo é de $\mathrm{Cr} \$ 300.000$, sejam os seguintes: 


\begin{tabular}{|ccc|}
\hline Produtos & $\begin{array}{c}\text { Receita total } \\
\text { Crs }\end{array}$ & $\begin{array}{c}\text { Custo variável } \\
\text { Cr\$ }\end{array}$ \\
V & 100.000 & 50.000 \\
X & 120.000 & 30.000 \\
Y & 150.000 & 20.000 \\
$Z$ & $\underline{230.000}$ & $\underline{100.000}$ \\
\hline & $\underline{600.000}$ & $\underline{200.000}$ \\
\hline
\end{tabular}

A margem de contribuiçāo seria $\mathrm{Cr} \$$ 400.000 (Cr $\$ 600,00$ - Cr\$200.000) e, portanto, o índice médio da margem de contribuição total seria de aproximadamente $66,7 \%$ (para ser mais exato, 66,667\%). Logo, o ponto de equilíbrio total, considerandose a mesma porcentagem de produtos vendidos, seria alcançado com a venda de aproximadamente $\mathrm{Cr} \$ 450.000$ (Cr $\$ 300.000$ : : $66,667 \%)$.

Conseqüentemente, poderíamos estudar graficamente essa situação, conforme o indica o gráfico 3 , onde a inclinação da reta do lucro é dada pelo índice médio da margem de contribuiçāo total da empresa. Note-se que, quando as vendas equivalem a zero, existe um prejuízo igual a $\mathrm{Cr} \$$ 300.000 (que é o custo fixo, mostrado no canto inferior do lado esquerdo do gráfico), prejuízo que vai diminuindo à medida que as vendas aumentam, até anular-se no ponto de equilibrio (onde as vendas são de Cr\$ 450.000), e a partir deste, existirá lucro, medido na escala, no canto superior do lado direito do gráfico."

Porém, apesar do interesse e da utilidade das informaçōes acima, não respondemos às perguntas feitas e principalmente não sabemos quais dos produtos é o mais lucrativo para a empresa em consideração, a qual está obtendo um lucro líquido total de aproximadamente $17 \%$ em relação às vendas.

Porcentagem obtida segundo o cálculo abaixo:

\begin{tabular}{|c|c|}
\hline Vendas.... & 600.000 \\
\hline (-) Custo variável.: & 200.000 \\
\hline Margem de contribuiçāo.. & 400.000 \\
\hline (-) Custo fixo... & 300.000 \\
\hline . Lucro líquido........ & 100.000 \\
\hline
\end{tabular}

Ora:

$\frac{\operatorname{Cr} \$ 100.000}{\operatorname{Cr} \$ 600.000} \times 100=16,667 \%=17 \%$

\section{Grófico 3}

Índice de margem, de contribuiçāo total e ponto de equilíbrio

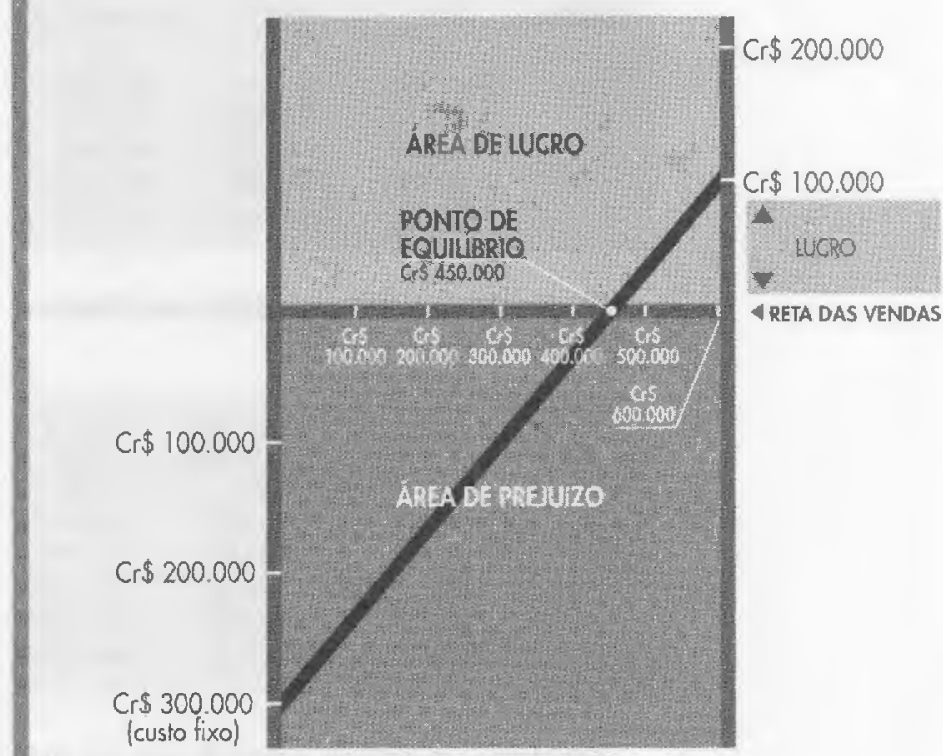

Uma das maneiras de apropriar o custo fixo total aos vários produtos, para então obter a lucratividade de cada um deles, seria através do cálculo do custo variável de cada mercadoria em relação ao total do custo variável dos quatro produtos, ou seja:

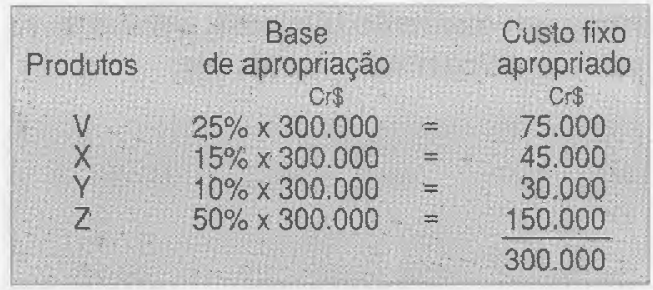

As porcentagens foram calculadas da seguinte maneira:

\begin{tabular}{|c|c|}
\hline $\begin{array}{l}\text { Produtos } \\
\text { V }\end{array}$ & $\frac{\operatorname{cr} \$ 50.000}{\operatorname{cr} \$ 200.000} \times 100=25 \%$ \\
\hline$x^{\prime}$ & $\frac{\operatorname{cr} \$ 30.000}{\operatorname{cr} \$ 200.000} \times 100=15 \%$ \\
\hline$Y$ & $\frac{C r \$ 20.000}{C+\$ 200.000} \times 100=10 \%$ \\
\hline$z$ & $\frac{\operatorname{Cr} \$ 100.000}{\operatorname{Cr} \$ 200.000} \times 100=50 \%$ \\
\hline
\end{tabular}

11. Esse tipo de gráfico é, às vezes, denominado de "Grático do lucro volume", como traduçāo da expressăo da língua inglesa Profitvolume graph. Todavia, esta denominaçāo pode dar margem a interpretaçōes errôneas, conforme a nota 5 . 
Consequientemente, teríamos a seguinte situação:

\begin{tabular}{|cccc}
\hline Produtos & $\begin{array}{c}\text { Receita } \\
\text { total }\end{array}$ & $\begin{array}{c}\text { Custo } \\
\text { total }\end{array}$ & $\begin{array}{c}\text { Lucro } \\
\text { (ou prejuizo) }\end{array}$ \\
& cos & crs & ors \\
V & 100.000 & 125.000 & $(25.000)$ \\
X & 120.000 & 75.000 & 45.000 \\
Y & 150.000 & 50.000 & 100.000 \\
Z & $\frac{230.000}{600.000}$ & $\frac{250.000}{500.000}$ & $\frac{(20.000)}{100.000}$ \\
\hline
\end{tabular}

Os resultados foram obtidos mediante $o$ seguinte cálculo:

\begin{tabular}{|c|c|c|c|}
\hline $\begin{array}{l}\text { Produtos } \\
\qquad \begin{array}{l}V \\
X \\
Y \\
Z\end{array}\end{array}$ & $\begin{array}{c}\text { Custo } \\
\text { variävel } \\
\text { Crs } \\
500.000 \\
30.000 \\
20.000 \\
100.000\end{array}$ & $\begin{array}{c}\text { Custo fixo } \\
\text { apropriado } \\
\text { Crs } \\
75.000 \\
45.000 \\
30.000 \\
150.000\end{array}$ & $\begin{array}{c}\text { Custo } \\
\text { total } \\
\text { cr\$ } \\
125.000 \\
75.000 \\
50,000 \\
250.000\end{array}$ \\
\hline & 200.000 & 300.000 & $500: 000$ \\
\hline
\end{tabular}

Portanto, chega-se à conclusão de que somente os produtos $\mathrm{X}$ e $\mathrm{Y}$ proporcionam lucros, enquanto que $\mathrm{V}$ e $\mathrm{Z}$ resultam em prejuízos de $\mathrm{Cr} \$ 25.000$ e $\mathrm{Cr} \$ 20.000$ respectivamente $e$, naturalmente, não seria interessante vendê-los.

Todavia, se a base empregada para apropriação do custo fixo for outra, por exemplo, a porcentagem da receita proporcionada pelos produtos, individualmente, em relação ao total das receitas dos quatro, teríamos um resultado diferente, conforme se percebe pelos resultados abaixo:

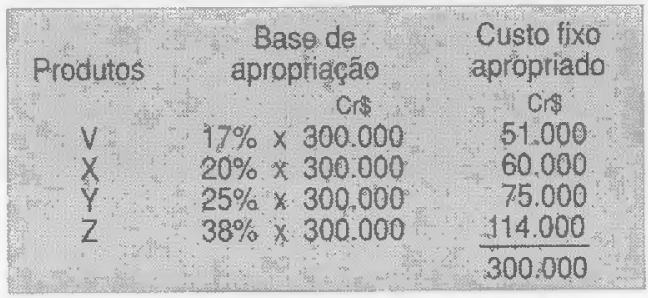

O cálculo das porcentagens foi feito da seguinte maneira:

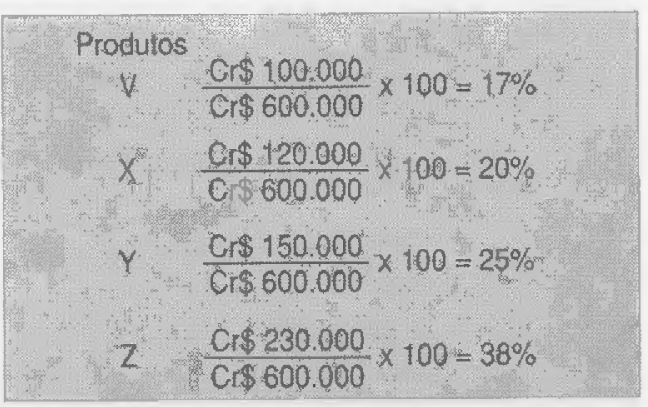

Logo, a situação de cada produto seria:

\begin{tabular}{|c|c|c|c|}
\hline $\begin{array}{c}\text { Produto } \\
\mathrm{V} \\
\mathrm{X} \\
\mathrm{Y} \\
\mathrm{Z}\end{array}$ & $\begin{array}{c}\text { Receita } \\
\text { total } \\
\text { Crs } \\
100.000 \\
120.000 \\
150.000 \\
230.000 \\
\end{array}$ & $\begin{array}{r}\text { Custo } \\
\text { total } \\
\text { Cos } \\
101.000 \\
80.000 \\
95.000 \\
214.000 \\
\end{array}$ & $\begin{array}{c}\text { Lucro } \\
\text { (ou prejuizo) } \\
\text { crs } \\
(1,000) \\
30.000 \\
55.000 \\
16.000 \\
\end{array}$ \\
\hline & 600,000 & 500.000 & 100.000 \\
\hline
\end{tabular}

Os números foram obtidos mediante o seguinte raciocínio:

\begin{tabular}{|c|c|c|c|}
\hline $\begin{array}{c}\text { Produ } \\
V \\
X \\
Y \\
Z\end{array}$ & $\begin{array}{c}\text { Custo } \\
\text { varíável } \\
\text { Cr's } \\
50.000 \\
30.000 \\
20.000 \\
100,000\end{array}$ & $\begin{array}{c}\text { Custo fixo } \\
\text { apropriado } \\
\text { Crs } \\
51.000 \\
60.000 \\
75.000 \\
114.000\end{array}$ & $\begin{array}{r}\text { Custo } \\
\text { total } \\
\text { chs } \\
101,000 \\
90.000 \\
95.000 \\
214.000\end{array}$ \\
\hline & 200.08 & 300.000 & 500.000 \\
\hline
\end{tabular}

Então, o produto $V$, que anteriormente apresentava um prejuízo de Cr\$25.000, mostra agora somente $\mathrm{Cr} \$ 1.000$ de prejuí$z o$, enquanto que o produto $Z$, que também anteriormente apresentava um prejuizo (Cr\$20.000), agora mostra um lucro de Cr\$ 16.000. Por outro lado, os produtos " $X$ " e "V", que eram lucrativos por Cr $\$ 45.000 \mathrm{e}$ Cr $\$ 100.000$, respectivamente, agora apresentam lucros de somente $\mathrm{Cr} \$ 30.000$ e $\mathrm{Cr} \$$ 55.000 , respectivamente.

Os administradores de empresa que trabalham no campo de administração contábil e financeira têm utilizado, com muito proveito, as contribuições recebidas do campo da ciência econômica - apesar das disparidades encontradas nos conceitos e definições dos economistas e dos próprios administradores de empresa.

Qual, então, é o prejuízo que a empresa está tendo, fabricando e/ ou vendendo Ve $Z$ ? É conveniente continuar com esses produtos na linha, em vista dos prejuízos? Tais perguntas freqüentemente são feitas pelos administradores quando enfrentam situação semelhante à descrita. 
Na verdade, nem $V$ ou $Z$ dão prejuízos. O problema todo foi no rateio dos custos fixos, que distorcem completamente os resultados, pois não se pode raciocinar modernamente em termos de custos totais por produto mas, sim, em termos de margem $e$ índice de margem de contribuição.

No caso da empresa que estamos exemplificando, teríamos especificamente:

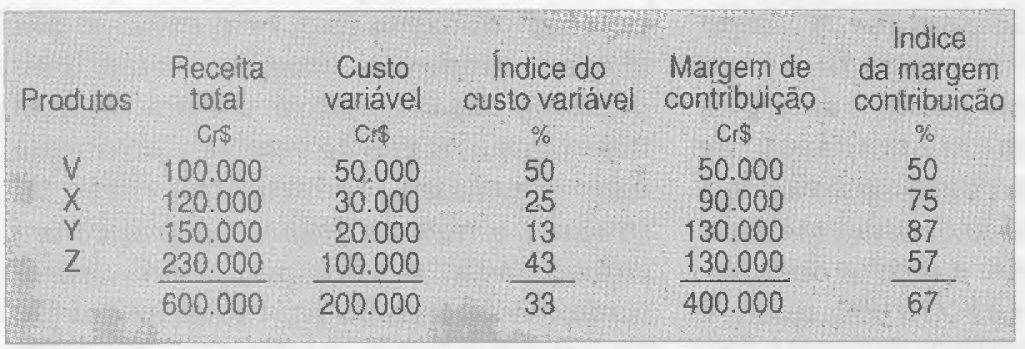

Portanto, V contribuiu com Cr $\$ 50.000$ e Z com Cr\$ 130.000 para "cobrix" o custo fixo e proporcionar lucro para a empresa.

No caso em tela, o lucro total da empresa é de Cr\$100.000: quanto do mesmo resulta da produção e/ou venda de V e Z ?

Se esses dois produtos nāo tivessem sido fabricados e/ou vendidos, não seria o lucro total da empresa diminuído, uma vez que eles "contribuem" com Cr\$50.000 e Cr $\$ 130.000$, respectivamente, para cobrir o custo fixo total e ainda para o lucro total da firma?

Esse tipo de análise mostra o erro que pode ser cometido quando trabalhamos com custos totais e não levamos em consideração a margem e o índice de contribuição de cada produto.

Essa análise pode ainda ser complementada por um gráfico, o qual - segundo a opinião do autor - é um pouco complicado, porém, uma vez tendo-se conseguido compreender os princípios básicos do mesmo, pode ser de grande valia. ${ }^{12}$

Vejamos como foi construído o gráfico 4, ao mesmo tempo que daremos dele explicação:

- A linha horizontal representa as vendas, separando a área do lucro e prejuízo.

- Partindo-se da linha vertical do lado esquerdo e abaixo da linha horizontal das vendas, na quantia de $\mathrm{Cr} \$ 300.000$ (custo fixo), traça-se uma reta até atingir a quantia de Cr\$100.000 (lucro) na linha vertical do lado direito e acima da reta horizontal das vendas. Observe-se que a

\section{Grófico 4}

reta traçada cruza a linha horizontal das vendas na quantia de $\mathrm{Cr} \$ 450.000$ que é o ponto de equilibrio; portanto, essa reta, assim traçada, terá a sua inclinação de acordo com o índice médio de margem de contribuição total da empresa.

- Traça-se, em linha pontillhada, a margem de contribuição de cada produto, ini$\mathrm{ci}$ ando-se pelo produto que apresenta o maior indice de maxgem de contribuição, o qual não coincide, necessariamente, sempre com aquele de maior margem de contribuição e, portanto, inicia-se com o mesmo, partindo de $\mathrm{Cr} \$$ 300.000 (custo fixo) até atingir o ponto equivalente a $\mathrm{Cr} \$ 170.000$, abaixo do volume de venda igual a $\mathrm{Cr} \$ 150.000$. Isto significa que foram "recuperados" $\mathrm{Cr}$ \$ 130.000 do custo fixo. Note-se que esses Cr\$ 130.000 sāo a margem de contribuição do produto $Y$.
12. Segundo Dickey - DICKEY, R. I. (org.) Accountants' Cost Handbook, $2^{\circledR}$ ediçáo, Nova lorque, The Ronald Press Company, 1960, seção 18, p. 22-foram A. Matz, O. J. Curry e G W. Frank os precursores deste tipo de grático, o qual atualmente é utilijzado por vários outros autores.

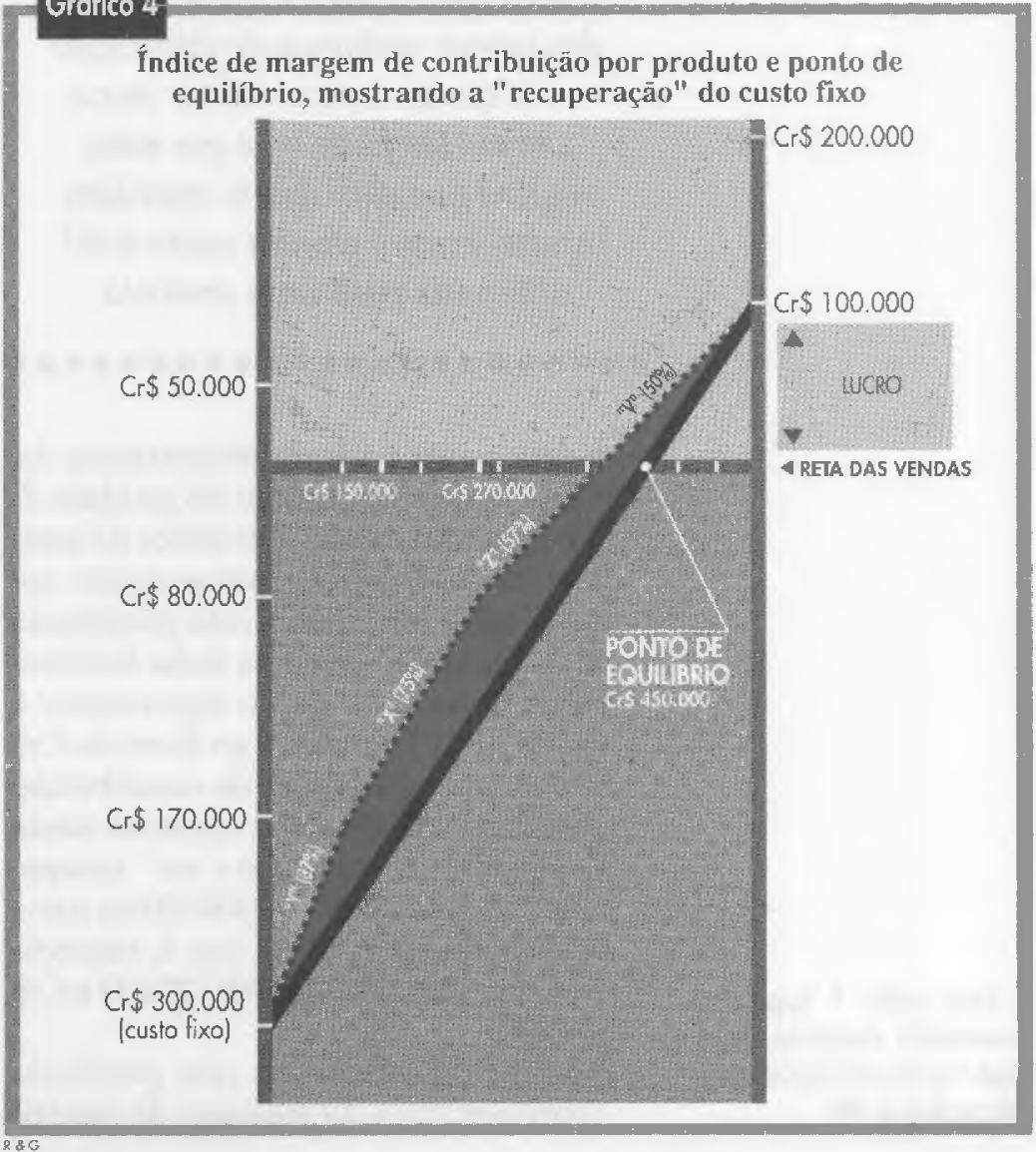


- Partindo-se do local onde terminou a reta pontilhada representativa da margem de contribuição do produto $Y$, começa a reta pontilhada representativa da margem de contribuição do produto que tenha o segundo maior índice da margem de contribuição, que no caso é $X$, e termina no ponto equivalente a $\mathrm{Cr} \$ 80.000$, pois restavam Cr $\$ 170.000$ do custo fixo a ser "coberto" e com a margem de contribuição de $\mathrm{Cr} \$ 90.000$ do produto " $\mathrm{X}$ ", resta apenas Cr\$80.000 de custo fixo a ser "recuperado". A reta pontilhada representativa da margem de contribuição de $X$ termina não só no ponto equivalente $a$ Cr\$ 80.000 do custo fixo, como também no ponto equivalente e abaixo do volume de vendas de Cr\$270.000, que é a quantia representativa da soma das vendas de $\mathrm{Ye} X$, ou seja, respectivamente $\mathrm{Cr} \$ 150.000$ e Cr $\$ 120.000$.

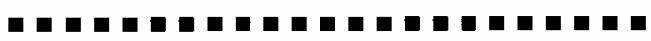

Aqueles que estão familiarizados com a contabilidade de custos sabem muito bem que diversas são as bases para a apropriação dos custos indiretos de fabricação

- os quais, em sua maior parte, são custos fixos - e por mais lógicas que elas sejam, resultam quase sempre em um custo total diferente para cada produto.

13. Conf. LANG, T. (org.) Cost Accountant's Handbook. Nova lorque, The Ronald Press Company, 1954, seçăo 2, p. 107. buição de $\mathrm{V}$, até atingir o ponto equivalente à venda de mais $\mathrm{Cr} \$ 100.000$, ou seja, Cr\$ 600.000; e até alcançar o lucro adicional de $\mathrm{Cr} \$ 50.000$, ou seja, o ponto de lucro total de Cr $\$ 100.000$.

Naturalmente, se o indice de margem de contribuição de qualquer produto fosse igual a zero, a linha pontilhada representativa do mesmo seria horizontal e paralela à reta das vendas, pois não haveria "recuperação" do custo fixo, bem como se por absurdo o índice da margem de contribuição fosse negativo, isto é, o custo variável maior que a receita de vendas, é óbvio que não compensaria produzir e/ou vender tal produto e mesmo assim, no gráfico em consideração, a linha pontilhada representativa do mesmo teria uma inclinação de cima para baixo, mostrando uma diminuição do lucro.

Desse modo, apesar das complicações envolvidas na compreensão desse último gráfico, foi possível mostrar quão errônea é a idéia de se analisarem os custos dos produtos em função dos seus custos totais, pois, conforme a maneira de apropriar os custos fixos, diferentes serão os resultados obtidos, os quais distorcem completamente a realidade.

É interessante agora observar o caso de uma empresa da vida real, que tinha um índice médio da margem de contribuição total de $37 \%$, o que resultava em um lucro líquido total de $3,7 \%$ em relação às vendas. Fazendo uma análise da maneira indicada no artigo, descobriu-se que aproximadamente metade de seus produtos apresentavam um índice da margem de contribuição de $51 \%$ e os produtos restantes $26 \%$. Ora, aumentando seus esforços de vendas nos produtos de maior margem de contribuição, a empresa conseguiu aumentar seu índice médio da margem de contribuição total de $37 \%$ para $44 \%$ - o que resultou em um lucro líquido sobre vendas de $10,7 \%$, isto é, quase triplicou essa última porcentagem. Observe-se que tudo isso foi obtido sem nenhum aumento nos preços unitários de venda, sem redução nos custos de fabricação e sem aumento no total do volume monetário de vendas. ${ }^{13}$

\section{CONCLUSÕES}

Os administradores de empresa que trabalham no campo de administração 
contábil e financeira têm utilizado, com muito proveito, as contribuições recebidas do campo da ciência econômica - apesar das disparidades encontradas nos conceitos e definições dos economistas e dos próprios administradores de empresa.

Uma dessas contribuições foi para a análise das relações entre custo-volumelucro, onde se considera o ponto de equilíbrio apenas como um tópico dessas relações, surgindo também os conceitos de margem e respectivo índice de contribuição, área de significância dos dados etc.

Focalizamos principalmente a falácia da análise pelo custo total, mostrando que conforme os custos fixos sejam rateados aos vários produtos de uma empresa, diferente será a lucratividade de cada um deles, bem como foi demonstrado que somente o índice da margem de contribuição de cada produto é que resolverá a questão.

Aqueles que estão familiarizados com a contabilidade de custos sabem muito bem que diversas são as bases para a apropriação dos custos indiretos de fabricação - os quais, em sua maior parte, são custos fixos - e por mais lógicas que elas sejam, re- sultam quase sempre em um custo total diferente para cada produto.

Não é à toa que a contabilidade de custos ortodoxa tem sofrido vários ataques, principalmente por aqueles que optam pelo chamado "custeio direto" 14 , pois nesse último sistema não se apropriam os custos fixos aos vários produtos mas, sim, trabalha-se tão somente com os custos variáveis e consideram-se os custos fixos como uma despesa do exercício ligado mais à empresa em si e não a cada produto individualmente.

O leitor pode perceber agora que, indiretamente, adotamos o ponto de vista dos defensores do custeio direto na discussão dos tópicos apresentados nesse artigo, pois, conforme Haseman mesmo o afirma, o gráfico e o conceito do índice da margem de contribuição têm muitos pontos de vista idênticos com as técnicas de custeio direto. ${ }^{15}$

Esperamos com isso ter contribuído para o aprimoramento das decisões a serem tomadas pelos administradores de empresa brasileiros, quando do estudo do comportamento da lucratividade de cada produto. $\square$
14. Custeio diretoé tradução do conceito conhecido por direct costing, utilizado principalmente por autores norte-americanos, emarginal costing, o qual é empregado preferivelmente por autores ingleses.

15. Cf. HASEMAN, W. C. Management Uses of Accounting. Boston, Allyn and Bacon, Inc., 1963, p.590.

\title{
Informacōes selecionadas à venda.
}

\begin{abstract}
A Fundação Getulio Vargas dispõe de publicações da FAO e da Unesco em inglês, francês e espanhol, sobre os seguintes temas:
\end{abstract}

FAO • Agricultura • Produção e Proteção Vegetal • Produção e Saúde Animal - Florestas • Pesca • Fomento de Terras e Águas • Desenvolvimento Econômico e Social • Alimentação e Nutrição • Obras gerais • Publicações Oficiais.

UNESCO • Educação • Ciências • Ciências Sociais • Cultura • Comunicação • Documentação, Bibliotecas e Arquivos • Publicações Oficiais.

Consulte-nos para maiores informações:

Editora da FGV

Cx. Postal 9052, 20000 - Rio de Janeiro, RJ, Tel.: (021) 551-0698 